\title{
Mechanical valves in the pulmonary position: An international retrospective analysis
}

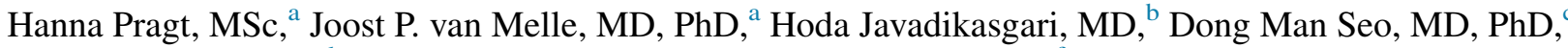 \\ John M. Stulak, MD, ${ }^{\mathrm{d}}$ Igor Knez, MD, PhD, ${ }^{\mathrm{e}}$ Jürgen Hörer, MD, PhD, ${ }^{\mathrm{f}}$ Christian Muñoz-Guijosa, PhD, ${ }^{\mathrm{g}}$ \\ Mahyar G. Dehaki, MSc, ${ }^{b}$ Hong Ju Shin, MD, PhD, ${ }^{c}$ Joseph A. Dearani, MD, ${ }^{\mathrm{d}}$ Maziar G. Dehaki, MD, ${ }^{f}$ \\ Petronella G. Pieper, MD, PhD, ${ }^{\mathrm{a}}$ Christine Eulenburg, $\mathrm{PhD},{ }^{\mathrm{h}}$ Laura Dos, $\mathrm{MD}, \mathrm{PhD},{ }^{\mathrm{g}}$ and \\ Tjark Ebels, MD, $\mathrm{PhD}^{\mathrm{a}}$
}

\section{ABSTRACT}

Objective: Life expectancy of patients with congenital heart disease has improved over the past decades, increasing the need for a durable pulmonary prosthetic valve. Biological valves in various forms have become the valve of choice for pulmonary valve replacement (PVR), but structural valve deterioration is unavoidable in the long term. Use of a mechanical valve could be an alternative, but data on long-term outcomes are sparse.

Methods: We retrospectively collected and analyzed data on 364 patients with mechanical valves implanted in the pulmonary position between 1965 and 2014. The data originate from medical centers in Barcelona (Spain), Graz (Austria), Groningen (the Netherlands), Munich (Germany), Rochester (United States), Seoul (Republic of Korea), and Tehran (Iran).

Results: Median follow-up duration was 4.26 years (range, 0-27 years), mean age at implantation was $27.16 \pm 12.2$ years. Tetralogy of Fallot was the most common primary cardiac diagnosis, with a subgroup of $69.8 \%$. Freedom from valvular thrombosis was $91 \%$ (95\% confidence interval [CI], 87\%-94\%) at 5 years and $86 \%(95 \% \mathrm{CI}, 81 \%-91 \%)$ at 10 years post-PVR. With a success rate up to $88 \%$, thrombolysis was a successful therapy. Freedom from reoperation was $97 \%(95 \% \mathrm{CI}, 94 \%-99 \%)$ at 5 years post-PVR and $91 \%(95 \% \mathrm{CI}, 85 \%-$ $95 \%)$ at 10 years.

Conclusions: Mechanical PVR is associated with a limited risk of valvular thrombosis. Thrombolysis was an effective treatment in the majority. (J Thorac Cardiovasc Surg 2017;154:1371-8)

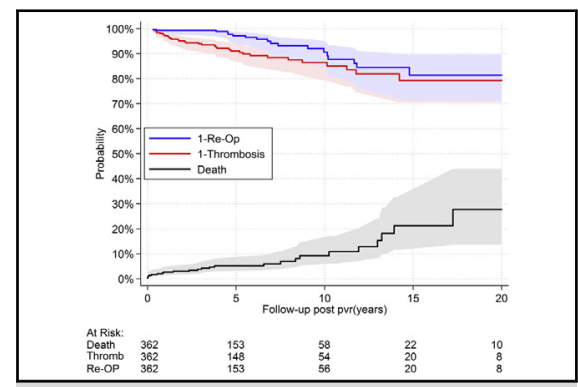

Cumulative incidence analyses for death, reoperation, and valvular thrombosis.

\section{Central Message}

MPVR is associated with a limited risk of valvular thrombosis. When this happened, thrombolysis was an effective treatment in the majority of patients.

\section{Perspective}

Literature on the long-term behavior of the different pulmonary prosthetic valves is scarce, especially on mechanical valves. With this study, we highlight the medium- to long-term performance of mechanical valves in the pulmonary position. Our results show a limited risk of valvular thrombosis and promising results for thrombolytic treatment. A mechanical valve can be a valid option for pulmonary valve replacement in selected patients.

See Editorial Commentary page 1379.

See Editorial page 1368.
Pulmonary valve replacement (PVR) is among the most common procedures in patients with right-sided congenital heart disease. ${ }^{1,2}$ No valve prostheses have been designed

\footnotetext{
From the ${ }^{\mathrm{a} C e n t e r}$ for Congenital Heart Diseases and ${ }^{\mathrm{h}}$ Medical Statistics and Decision Making, University Medical Center Groningen, University of Groningen, Groningen, The Netherlands; 'bepartment of Cardiovascular Surgery, Heart Valve Disease Research Center, Rajaie Cardiovascular Medical and Research Center, Iran University of Medical Sciences, Tehran, Iran; ${ }^{c}$ Department of Cardiovascular Surgery, Konkuk University Medical Center, Seoul, Republic of Korea; ${ }^{\mathrm{d} D i v i s i o n ~ o f ~}$ Cardiovascular Surgery, Mayo Clinic and Foundation, Rochester, Minn; ${ }^{\mathrm{e} D i v i s i o n}$ of Cardiac Surgery, Medical University of Graz, Graz, Austria; ${ }^{\mathrm{f}}$ Department of Cardiovascular Surgery and Pediatric Cardiology and Congenital Heart Disease, German Heart Center at the Technical University, Munich, Germany; and ${ }^{\mathrm{g}}$ Inte-
}

specifically for the pulmonary position, for which reason aortic valve prostheses (both tissue and mechanical) are usually used in the pulmonary position. Exceptions are 


\section{Abbreviations and Acronyms}

INR = international normalized ratio

IOD = inner orifice diameter

LVEF $=$ left ventricular ejection fraction

MPVR $=$ mechanical pulmonary valve replacement

PVR = pulmonary valve replacement

TAPSE $=$ Tricuspid Annular Plane Systolic

\section{Excursion}

ToF $\quad=$ tetralogy of Fallot

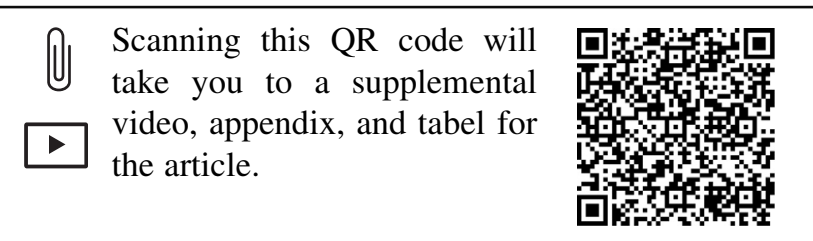

jugular venous xenograft valves that are available in a limited size range of 12 to $22 \mathrm{~mm}$ diameter and pulmonary allografts (homografts). Aortic tissue prosthetic valves in various models and allografts have been the valves of choice for particularly adult $\mathrm{PVR}^{2}$ because of a low risk of thrombosis without the need for anticoagulation. However, tissue valves have a limited lifespan caused by structural valve degeneration, ${ }^{3,4}$ which seems to occur earlier in the pulmonary than in the aortic position, rendering reinterventions unavoidable in all but elderly patients.

Mechanical prosthetic valves have been the gold standard for left-sided valve replacement in patients younger than age 60 years and could be a viable alternative to bioprostheses for patients in need of a PVR, particularly for patients with high surgical risk and patients already using anticoagulation agents. However, there are serious concerns about the higher risks of valvular thrombosis in right-sided mechanical valves as well as the bleeding risk resulting from lifelong anticoagulation use.

A recent meta-analysis on mechanical PVR (MPVR) showed an average valvular thrombosis occurrence of $2.2 \%$ at an average mean follow-up of 73 months (range, 8-180 months). ${ }^{5}$ However, this study was limited by a stark heterogeneity between studies and no time-related analysis was possible. A large study on the long-term functionality of MPVR is missing in the current literature.

The objective of this study was to evaluate medium- to long-term results of MPVR, using a large multicenter database combining updated data from the 7 largest studies worldwide from 2009 to $2015,,^{6-12}$ with a focus on valvular thrombosis as a primary end point. Thrombolysis, reoperation, and death were chosen as secondary end points because death is more associated with cardiac failure than with the prosthetic valve, whereas thrombolysis and reoperation are the result of the primary end point.

\section{METHODS \\ Study Design}

This study was designed as a multicenter retrospective study to observe the long-term functionality of a first MPVR. The primary end point was first valvular thrombosis, whereas secondary end points were thrombolysis, reoperation, and mortality. To minimize patient-related factors (such as thrombophilia), follow-up of second mechanical valves introduced at reoperation were not further analyzed. All corresponding authors of articles with a minimum of 15 mechanical pulmonary valves published between May 2009 and May 2015 $5^{6-12}$ agreed to participate in this retrospective chart review study, where the data were to be completed and updated from the time of their original publication. Patients diagnosed with carcinoid heart disease were excluded from the study due to the poor prognosis associated with carcinoid heart disease. Data transfer agreements are in place between all institutions and the University Medical Center Groningen.

\section{Data Collection}

All data were de-identified and compiled at the time of collation into the clinical database. Institutional review board approval was obtained by each separate institution before the collection of the data. Applicable legislation in the Netherlands stipulates that retrospective anonymized chart research is not subjected to institutional review board review. Ethics review was not deemed necessary upon question of individual ethics review boards. Data were collected retrospectively, using electronic and paper patient records. No identifiers were linked to patients in this collective database. Centers from the following towns contributed to this study: Barcelona, Spain; Graz, Austria; Groningen, The Netherlands; Munich and Lübeck, Germany; Rochester, Minnesota; Seoul, Republic of Korea; and Tehran, Iran. Data were collected and entered by the individual centers in a predetermined data submission file. We used the following parameters:

- Patient characteristics: age, gender, original diagnosis, previous surgeries, concomitant medication, and previous pregnancies.

- Procedural information: prosthetic valve brand, model and labeled size, date of implantation, concomitant procedures, complications, antithrombotic regimen, tricuspid annular plane systolic excursion (TAPSE), left ventricular ejection fraction (LVEF), and postoperative valve flow velocity, determined by continuous wave Doppler echocardiography.

- Follow-up information: valvular thrombosis, death, cause of death, valve replacement, thrombolysis of valvular thrombosis, date of the last follow-up visit, and pregnancies.

Transthoracic echocardiography was recorded within 1 year postoperatively. Local protocols were followed for obtaining and evaluating the echocardiographic images. Right ventricular systolic dysfunction was defined as TAPSE $\leq 16$. Moderately impaired left ventricular systolic dysfunction was defined as a LVEF $\leq 45 \%$ and severe dysfunction as a LVEF $<30 \%$. The variable "thrombosis" also includes pannus because the difference is often not obvious.

Labeling of prosthetic heart valves has changed over the years, although not all manufacturers adhere to the applicable International Standards Organization standards. The tissue annulus diameter of the patient is meant to reflect the labeled size. Thus, the labeled size reflects the inner orifice diameter (IOD) in supra-annular valves and the outer diameter in intra-annular valves. To take into account as many aspects as possible, we collected the IOD of all prosthetic valves from the manufacturer's specifications. Thus, IOD was chosen instead of the in vitro determined effective orifice area because of additional inconsistencies in the applicable methods used for measuring the effective orifice area. All data files were merged into 1 database and prepared for analysis at the University Medical Center Groningen. 
TABLE 1. Baseline characteristics and end points, distribution between centers

\begin{tabular}{|c|c|c|c|c|c|c|c|c|}
\hline & Barcelona & Graz & Groningen & Munich & Rochester & Seoul & Tehran & Total \\
\hline $\mathrm{N}$ & 34 & 22 & 65 & 19 & 52 & 53 & 119 & 364 \\
\hline Age at PVR, y & $35.1 \pm 10.8$ & $23.5 \pm 6.5$ & $34.1 \pm 12.0$ & $25.6 \pm 9.6$ & $31.6 \pm 14.1$ & $13.9 \pm 5.8$ & $25.96 \pm 9.3$ & $27.16 \pm 12.2$ \\
\hline Gender, male & $70.6 \%$ & $77.3 \%$ & $60 \%$ & $68.4 \%$ & $61.5 \%$ & $67.9 \%$ & $58.8 \%$ & $63.5 \%$ \\
\hline Follow-up, y & $7.5(0-27.4)$ & $5.6(0-9.3)$ & $6.2(0-21.3)$ & $12.6(8.1-15.9)$ & $6.4(0-24.76)$ & $4.9(0.4-26.1)$ & $2.3(0-5.7)$ & $4.26(0-27.4)$ \\
\hline Previous surgeries & $0.91 \pm 0.5$ & $2.0 \pm 0.9$ & $1.6 \pm 0.8$ & $3.2 \pm 1.5$ & $2.2 \pm 1.2$ & $1.9 \pm 1.2$ & $1 \pm 0$ & $1.6 \pm 1.0$ \\
\hline Labeled valve size, $\mathrm{mm}$ & $23(21-29)$ & $25(21-29)$ & $25(21-29)$ & $23(21-27)$ & $25(21-33)$ & $23(17-27)$ & $25(21-29)$ & $25(17-33)$ \\
\hline Target INR & $2.5-3.5$ & $3.5-4$ & $2.4-4$ & $3-4.5$ & $3 / 3.5^{*}$ & $2-3$ & $2.3-3.5$ & \\
\hline
\end{tabular}

$P V R$, Pulmonary valve replacement; $I N R$, international normalized ratio. *Patients with concomitant tricuspid valve replacement.

\section{PVR Procedures}

Operative procedures and valvular selection were performed according to local standards at the time of surgery. ${ }^{6-12}$ Uniformly, PVR was performed through a median sternotomy with the use of cardiopulmonary bypass. Follow-up visits were scheduled regularly according to local guidelines. International normalized ratio (INR) was targeted between 2.3 and 4.5 for all centers; Table 1 shows target INR levels for the individual centers. ${ }^{6-12}$

\section{Thrombolysis}

Protocols regarding thrombolysis have changed over time, due to the long period of inclusion and follow-up period of this study. No uniform thrombolysis protocol was present in all inclusion sites except for Munich and Tehran (Appendix E1).

\section{Statistics}

Continuous data are presented as means with standard deviations or medians with range, as appropriate. Frequencies are displayed as absolute numbers and percentages. Follow-up time was calculated between the date of PVR and the date of last follow-up, valvular thrombosis, redo-PVR, or death. Survival analyses were performed on a patient level. Competing risk analysis techniques were applied for the end points. Cumulative incidence curves were computed to display the event probabilities during the follow-up. Cox proportional hazard methodology was used to determine univariate and multivariate relationships between the covariates and time to event. Gender, hospital, and age were corrected for in our multivariate model. Most statistical analyses were performed using IBM-SPSS statistics version 22.0 (IBM-SPSS Inc, Armonk, NY). The cumulative incidence graph was generated using STATA version 14.0 (StataCorp LP, College Station, Tex).

\section{RESULTS}

We retrospectively collected data on 364 patients who received a first mechanical aortic valve prosthesis in the pulmonary position from 1965 to 2014 . The number of patients per center varied from 19 to 119 . Patient inclusion time periods varied widely across the different centers (Figure 1). The total number of patient-years was 2047 and there was a total of 35 first thromboses (1.7\%/patient-year; $95 \%$ confidence interval $[\mathrm{CI}], 1.2 \%-2.4 \%)$ and 20 reoperations (1.0\%/patient-year: $95 \%$ CI, $0.6 \%-1.5 \%)$.

Baseline characteristics are shown in Table 2. Mean age was $27.16 \pm 12.2$ years at the time of MPVR (range, 171 years). Tetralogy of Fallot ( $\mathrm{ToF}$ ) was the primary cardiac diagnosis in $69.8 \%$. In $94.9 \%$ (241 out of 254 ) of $\mathrm{ToF}$ cases, a total repair had been done before MPVR. The median number of prior cardiac surgeries was 1 (range, 0-7). In 10 cases, no previous procedures had been performed. Median follow-up was 4.26 years (range, 0-33 years), 152 patients had a follow-up of more than 5 years, and 58 patients had more than 10 years of follow-up. Of the female patients, 11 had been pregnant before the MPVR. Four patients were pregnant whilst having an MPVR. Two patients experienced valvular thrombosis relating to pregnancy.

There were 241 St Jude Medical (St Paul, Minn) valves implanted (66.2\%), 76 Sorin Carbomedics valves (LivaNova, London, United Kingdom) (20.9\%), 16 ATS valves (Medtronic, Dublin, Ireland) (4.4\%); 11 Sorin Bicarbon valves $(3.0 \%)$; 5 On-X valves (CryoLife Inc, Kennesaw, Ga) $(1.4 \%)$, and $1(0.3 \%)$ Duromedics valves (Edwards LifeSciences, Irvine, Calif), all of the bileaflet type. Eleven tilting disc valves were implanted: 7 Björk-Shiley $(1.9 \%$ [Pfizer, New York, NY]), 4 Omnicarbon (1.1\% [MedicalCV, Inver Grove Heights, Minn]), 2 caged-ball Starr-Edwards $(0.5 \%$ [Edwards LifeSciences]), and 1 Gott valved conduit was used. The median labeled valve size was $25 \mathrm{~mm}$ (range, 17-33 mm), the median IOD was $20.5 \mathrm{~mm}$ (range, 14.8-24.9 mm). Right ventricular outflow tract repair was the most frequently performed concomitant procedure (Table 2). Of all patients, $28 \%$ had an LVEF $\leq 45 \%$ postoperatively (Table 3 ). As anticoagulant, warfarin was used in 64.8\% $(\mathrm{n}=236)$, acenocoumarol in $105(28.8 \%)$, and phenprocoumon in $16(4.4 \%)$. One patient was only treated with acetylsalicylic acid and for 6 patients the

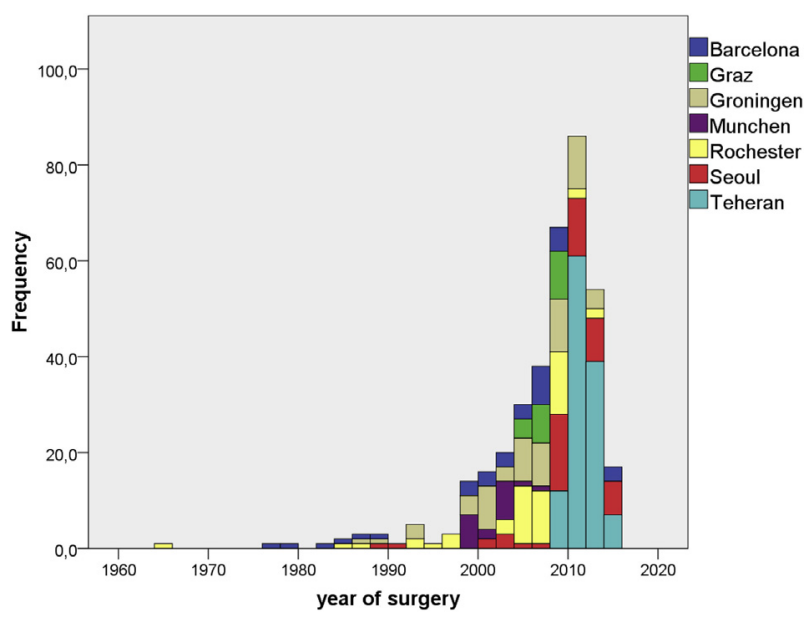

FIGURE 1. Pulmonary valve replacement by year of surgery, color coded by participating center. 
TABLE 2. Original diagnosis, previous procedures, and concomitant procedures

\begin{tabular}{lrc}
\hline & N & $\%$ \\
\hline Original diagnosis & & \\
Tetralogy of Fallot & 254 & 69.8 \\
Transposition of the great arteries & 8 & 2.2 \\
Pulmonary valve atresia & 27 & 7.4 \\
Pulmonary valve stenosis & 17 & 4.7 \\
Double outlet right ventricle & 13 & 3.6 \\
Truncus arteriosus & 22 & 6.0 \\
Aortic valve disease & 21 & 5.8 \\
Other & 7 & 1.9 \\
Previous procedures & & \\
Aortic pulmonary shunt & 53 & 14.3 \\
Pulmonary valvotomy & 40 & 11.0 \\
Total repair tetralogy of Fallot & 241 & 66.2 \\
Ross & 20 & 5.5 \\
Rastelli procedure & 20 & 5.5 \\
Patent ductus arteriosus correction & 4 & 1.1 \\
Aortic valve replacement & 21 & 5.8 \\
Mitral valve replacement & 4 & 1.1 \\
Pulmonary valve replacement & 89 & 24.5 \\
Tricuspid valve replacement & 7 & 1.9 \\
Other procedures & 70 & 19.2 \\
Concomitant procedures during mechanical pulmonary valve replacement \\
Right ventricular outflow tract repair & 114 & 31.3 \\
Tricuspid valve repair & 49 & 13.5 \\
Mechanical aortic valve replacement & 41 & 11.3 \\
Ventricular septal defect closure & 21 & 5.8 \\
Mechanical tricuspid valve replacement & 18 & 4.9 \\
Mechanical mitral valve replacement & 10 & 2.7 \\
Total repair tetralogy of Fallot & 6 & 1.6 \\
Rastelli procedure & 3 & 0.8 \\
Pacemaker implantation & 8 & 2.2 \\
Other procedures & 16.8 \\
\hline
\end{tabular}

anticoagulation regimen was unknown either due to immediate reoperation or to early operative mortality.

\section{Valvular Thrombosis}

There were 35 of $364(9.6 \%)$ reported cases of first valvular thrombosis. Median time between PVR and first valve thrombosis was 2.9 years (range, 0.3-23.2 years). Cox regression calculated freedom from first thrombosis at 5 years was $91 \%(95 \% \mathrm{CI}, 87 \%-94 \%)$, at 10 years, $86 \%(95 \% \mathrm{CI}, 81 \%-91 \%)$, and at 15 years $79 \%(95 \%$

TABLE 3. Postoperative transthoracic echocardiogram characteristics

\begin{tabular}{lcc}
\hline \multicolumn{1}{c}{ Parameter } & \multicolumn{1}{c}{ Result } & Valid N \\
\hline Pulmonary valve flow velocity, $\mathrm{m} / \mathrm{s}$ & $2.1 \pm 0.62$ & 302 \\
$\leq 16$ & $69.2 \%(128 / 185)$ & 185 \\
Left ventricular ejection fraction $\leq 30 \%$ & $3.1 \%(9 / 290)$ & 290 \\
Left ventricular ejection fraction $30 \%-45 \%$ & $25.9 \%(75 / 290)$ & 290 \\
Left ventricular ejection fraction $>45 \%$ & $71 \%(206 / 290)$ & 290 \\
\hline
\end{tabular}

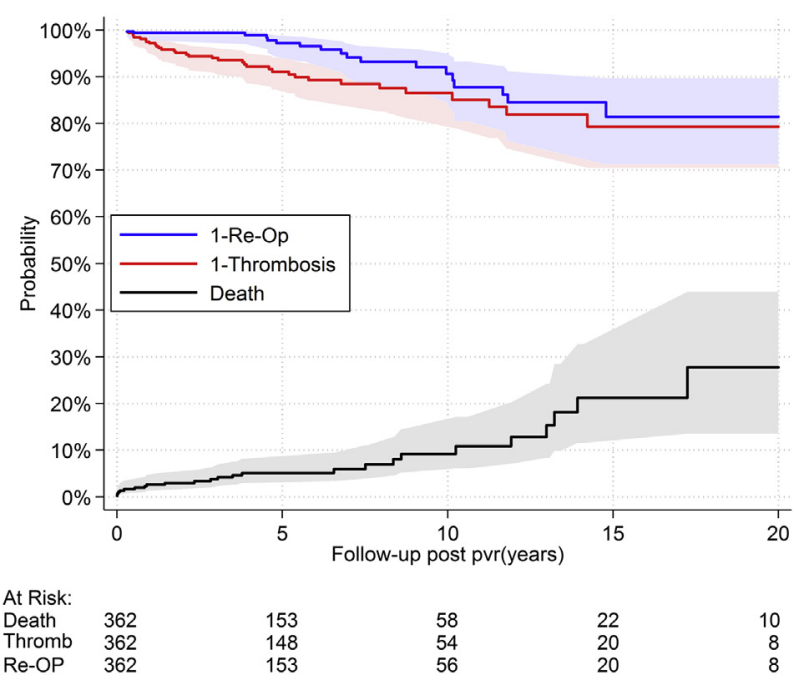

FIGURE 2. Competing risk analysis, for valvular thrombosis (Thromb), reoperation $(\mathrm{Re}-\mathrm{Op})$, and death. Incidences for reoperation and valvular thrombosis are presented as 1-Thrombosis and 1-ReOp.

CI, 70\%-87\%) (Figure 2 and Table E1). No valvular thrombosis occurred for the single patient taking acetylsalicylic acid. There seemed to be a relationship between labeled valve size and occurrence of thrombosis, but when repeating the analysis for the IOD, no relationship was found with valvular thrombosis (hazard ratio, 0.99; 95\% CI, 0.76-1.3; $P=.936$ ). We did detect a center effect in our study; however, when correcting for center, both as a fixed or random effect, there was no influence on outcome.

Inclusion of gender, age, year of implantation, primary cardiac diagnosis, valve brand, type of anticoagulation, simultaneous valve replacements, and prior surgeries and conduit resulted in no correlation of any variable with valvular thrombosis, both univariate nor multivariate.

In 26 of 35 cases $(74.3 \%)$ of valvular thrombosis, thrombolysis was performed, as shown in Figure 3. Thrombolysis was successful in 22 of 26 cases $(84.6 \%)$. In 4 cases, thrombolysis was unsuccessful and reoperation ensued. In 3 cases, reoperation was later necessary after initial successful thrombolysis (at 0.2, 3.7, and 6.2 years, respectively, after thrombolysis). In 1 case, there were 3 successful thrombolysis procedures. Median follow-up after first thrombolysis was 1.5 years (range, $0-7.6$ years).

\section{Reoperations}

In 20 of 364 cases $(5.5 \%)$ the prosthetic valve was replaced; 16 of $20(80 \%)$ reoperations were indicated by valvular thrombosis: 1 patient outgrew the prosthesis, the reason for reoperation in the remainder is unknown. The mean time to valve replacement was $7.6 \pm 5.5$ years. Freedom from reoperation at 5 years was $97 \%(95 \% \mathrm{CI}, 94 \%-99 \%), 91 \%$ at 10 years $(95 \% \mathrm{CI}, 85 \%-95 \%)$ and $81 \%$ at 15 years $(95 \%$ CI, $71 \%-90 \%$ ). Figure 2 shows the freedom from reoperations over time in a cumulative incidence graph depicting 


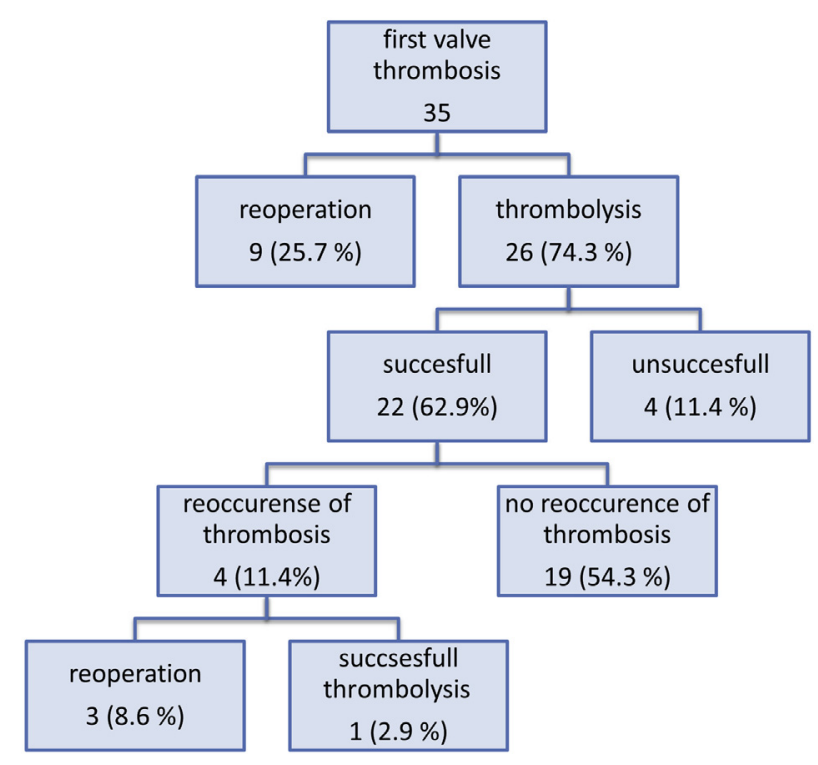

FIGURE 3. Flow chart of treatment of valvular thrombosis in pulmonary mechanical valves.

the competing risks. In 6 of 20 patients, their redo valve was an MPVR, which we chose not to include for further analysis. For the other patients, the valve received at reoperation is unknown due to the historical nature of this study. From the 20 patients who had a prior Ross operation, 16 patients had an MPVR in either the aortic or mitral position and were thus already taking anticoagulation medication, for 4 other patients there were different reasons to choose an MPVR.

\section{Mortality}

There were 31 of 364 (8.5\%) reported deaths, of which 7 of 31 occurred operatively (22.6\%), 15 of $31(48.4 \%)$ were cardiac deaths (right ventricle failure, arrhythmias, or sudden death), and in 9 cases the cause was unknown $(29.0 \%)$. Mean age at death was $40.3 \pm 16.0$ years (range, 5.3-75.5 years). Of the cardiac deaths, none were valverelated. There was 1 death due to pulmonary hemorrhage with INR level $>7$. There were no thrombosis-related deaths reported. Survival post-PVR at 5 years was $95 \%(95 \%$ CI, $92 \%-97 \%), 91 \%$ at 10 years $(95 \%$ CI, $85 \%-95 \%)$, and $79 \%$ at 15 years (95\% CI, 67\%-88\%) (Figure 2).

\section{DISCUSSION}

The unique size of this study was only possible by combining data from the 7 participating centers, from which we accumulated 364 patients who had a first MPVR performed from 1965 until 2014. By doing so, we created the largest comprehensive dataset so far on MPVR and we were able to provide the most realistic evaluation of mechanical prosthetic valves in the pulmonary position until now.

Valvular thrombosis has always been the major concern with the use of mechanical valves in the pulmonary position. The rate of thrombosis, despite anticoagulation, has always been reported to be appreciably higher than in the aortic position. We found a relatively linear rate of valvular thrombosis of about $1.7 \%$ per patient year. Dunne and colleagues ${ }^{5}$ published recently a meta-analysis of 19 studies up until 2013, but regrettably could not perform a detailed time-related analysis on the occurrence of valvular thrombosis, so that study does not provide insight into that crucial observation over time.

Our results confirm a higher incidence of valvular thrombosis for mechanical valves in the pulmonary position compared with the literature on aortic and mitral position; reported thrombosis incidences range between $0 \%$ and $0.6 \%$ per patient-year. ${ }^{13-17}$ However, we should be careful when comparing different populations, particularly because patients receiving a pulmonary valve in most cases have a more complex medical history and surgical background than have patients receiving aortic and mitral valves and, in addition, usually are much younger. On the other hand, thrombosis of right-sided prosthetic valves may be underdiagnosed because partial and nonobstructive thrombosis as well as minor emboli may remain subclinical for a long time. The higher propensity for thrombus formation in the right ventricle is most likely related to its lower pressures and the mechanism of mechanical valves. Whether or not the incidence of thrombus formation is also larger in tissue prostheses in the right ventricle is unknown.

Thrombolysis was found to be remarkably successful in our cohort, with a success rate of $84.6 \%$. The 2014 American Heart Association/American College of Cardiology guidelines advise fibrinolytic therapy as "reasonable" for thrombosed right-sided prosthetic heart valves, ${ }^{18}$ which might be changed to "recommended" based on our findings. We presume, because we have no evidence, that this might apply to the tricuspid position as well. Nonetheless, we should be aware that information on the complications of thrombolysis is not available and did not surface in the current study. More research is necessary on the longterm effect of thrombolysis on the treatment of valvular thrombosis.

Although we did not find any relevant predictors for valvular thrombosis, several factors could influence its occurrence. Local circumstances and practices could influence the occurrence of valvular thrombosis, most notably the availability of universally adequate antithrombotic services. In addition, the frequency of screening during the early stages after PVR could play a role in detecting and treating early thrombi. Noncompliance with anticoagulation therapy has been shown to play an important role in the incidence of valvular thrombosis. These factors could play an important role in the center effect we detected. Because the objective of this study was to analyze valves instead of centers, we lacked adequate parameters to make a valid analysis between centers.

Reintervention rates (both catheter-based and reoperation) in our study are lower than in the large 
TABLE 4. Relevant literature on biological pulmonary valve replacement

\begin{tabular}{|c|c|c|c|c|c|c|c|c|}
\hline First author & Country & $\begin{array}{c}\text { Publication } \\
\text { year }\end{array}$ & ToF $\%$ & $\begin{array}{c}\text { Inclusion } \\
\text { period }\end{array}$ & $\begin{array}{c}\text { Total } \\
\text { patients }\end{array}$ & Follow-up, y & Men & Age \\
\hline Nomoto $^{19}$ & USA & 2016 & 68.6 & $1996-2014$ & 611 & $3.0(1.1-5.3)$ & $367(60 \%)$ & $17.8(11.9-27.3)$ \\
\hline Oliver $^{21}$ & Spain & 2015 & 71 & $1990-2013$ & 114 & $7(13-34)$ & $68(59.6 \%)$ & $23(13-34)$ \\
\hline Schubert $^{22}$ & USA & 2015 & 57 & 2008-2013 & 84 & $2.5(0.2-5.6)$ & $52(61.9 \%)$ & $18.3(0.8-62.1)$ \\
\hline Babul-Narayan $^{20}$ & UK & 2014 & 100 & 1993-2010 & 220 & $\begin{array}{r}\text { Homograft } 4.3(1.6-9.4) \\
\quad x e n o g r a f t \\
2.4\end{array}$ & $128(58.2 \%)$ & $32(16-64)$ \\
\hline Sabate-Rotes ${ }^{23}$ & USA & 2014 & 100 & $1973-2012$ & 278 & $7.3 \pm 6.8(1-34)$ & $148(53 \%)$ & $31.4 \pm 16.4$ \\
\hline $\mathrm{Chen}^{24}$ & USA & 2013 & 53.4 & $1992-2008$ & 161 & $\begin{array}{l}\text { (months) porcine } \\
24(0.03-135), \\
\text { pericardial } 58(1-181)\end{array}$ & $\begin{array}{c}\text { Porcine } 48(65.7 \%), \\
\text { pericardial } \\
58(59.8 \%)\end{array}$ & $\begin{array}{c}\text { Porcine: } 19(4-66) \text {, } \\
\text { pericardial: } \\
16(0.5-72)\end{array}$ \\
\hline $\begin{array}{l}\text { Van de } \\
\text { Woestijne }^{25}\end{array}$ & NL & 2011 & 100 & $1987-2009$ & 126 & $8.1 \pm 5.6(0.04-21.2)$ & $72(57.1 \%)$ & $28.1 \pm 12.2$ \\
\hline Shinkawa ${ }^{26}$ & USA & 2010 & 64 & 2002-2009 & 73 & $2.6(0.2-8.0)$ & $44(60.2 \%)$ & $17.3(2.1-64.3)$ \\
\hline Fiore $^{27}$ & USA & 2008 & $?$ & $1995-2006$ & 82 & $\begin{array}{c}\text { (mo) Porcine } 20 \pm 27 \\
\text { pericardial } 42 \pm 21 \\
\text { homograft } 49 \pm 40\end{array}$ & $53(64.6 \%)$ & $22.2 \pm 13.0$ \\
\hline
\end{tabular}

ToF, Tetralogy of Fallot; $U K$, United Kingdom; $N L$, The Netherlands.

Nomoto study ${ }^{19}$ with 611 biological valves: our MPVR study showed $97 \%$ freedom of reoperation only at 5 years postoperatively and $91 \%$ at 10 years post-PVR. These observations were not equal for all valve brands. Nomoto reported a Kaplan-Meier estimate of $80 \%$ freedom from reintervention at 5 years for the Mitroflow (LivaNova, London, United Kingdom), but $80 \%$ at 8 years out for Perimount pericardial valves (Edwards Lifesciences). ${ }^{19}$ Studies with similar populations are heterogeneous and provide less information for comparison, but the impression is that their results vary between Nomoto and the work by Babu-Narayan, ${ }^{20}$ who reported much better results in a study of 220 patients. Table 4 presents recent relevant literature on biological valves in the pulmonary position. ${ }^{19-27}$ Because younger age has been associated with higher rates of tissue valve degeneration and subsequent replacement, we did not include studies with predominantly young children in Table 4 . Pulmonary homografts were only reported by Van de Woestijne and colleagues ${ }^{25}$ who reported an $83 \%$ freedom from homograft replacement at 10 years in an adult ToF population.

Although with biological valves a younger age at implantation is associated with higher rates of valve degeneration, ${ }^{21}$ we saw no association between age at implantation and reoperation for mechanical valves. Arguably, tissue valves offer the advantage of not needing anticoagulation, whereas future replacements could be performed by transcatheter valve-in-valve procedures. Although percutaneous procedures are currently fashionable, even medium-term results of these procedures are lacking, yet there is an emergence of articles on an associated elevated endocarditis risk of up to $3 \%$ per patient year. ${ }^{28-30}$ Current literature on longer-term results of tissue valve prosthetic performance in the pulmonary position (without valve-invalve procedure) is so heterogeneous as to preclude formal comparison with this study, but mechanical valves seem not to do worse. The obvious advantage of catheter-based tissue valve implantation is that the procedure is far less traumatic and patient recovery is more rapid. Future development of mechanical valve prostheses specifically designed for the right ventricle might even improve upon the current propensity for thrombosis of $1.7 \%$ per patient-year and reoperation of $1.0 \%$ per patient-year. Finally, a normal pulmonary valve is a larger valve than the aortic valve in each individual because of the lower pressures involved. Thus, there are probably limits to which we should narrow the pulmonary valve with valve-in-valve procedures without inflicting an undue burden on the right ventricle, particularly of young patients and on exercise.

Bleeding complications were not recorded in this study, which arguably constitutes a major limitation. The reason for not recording bleeding complications is the historic nature of the study, and many patient files were incomplete. In addition, many patients are and were not followed-up by cardiologists from the center performing the operation. On the contrary, many received follow-up from remotely located cardiologists and feedback about such complications is vastly incomplete. Because we knew any attempt at collecting data on bleeding would appreciably underestimate the incidence, we decided not to do so. However, because the target INR is usually in the range of mechanical mitral valve prophylaxis, we presumed the bleeding incidences to be in that range.

In our study, a relatively high percentage $(70 \%)$ of patients with available echocardiogram data appeared to have right ventricle systolic dysfunction 1 year after 
TABLE 4. Continued

\begin{tabular}{|c|c|c|c|c|c|c|c|c|c|c|}
\hline Porcine & Pericardial & Homograft & Mechanical & Other & $\begin{array}{c}\text { Freedom } \\
\text { reintervention } 5 \mathbf{y} \\
\end{array}$ & $\begin{array}{c}\text { Freedom } \\
\text { reintervention } 10 \mathrm{y}\end{array}$ & $\begin{array}{c}\text { Freedom } \\
\text { reintervention } 15 \text { y }\end{array}$ & $\begin{array}{c}\text { Survival } \\
5 \mathbf{y}\end{array}$ & $\begin{array}{c}\text { Survival } \\
10 \mathrm{y} \\
\end{array}$ & $\begin{array}{c}\text { Survival } \\
15 \mathrm{y}\end{array}$ \\
\hline & 611 & & & & $93.7 \%$ & $75.6 \%$ & & & & \\
\hline \multirow[t]{2}{*}{85} & & 21 & & 48 & $95 \%$ & $71 \%$ & $41 \%$ & & & \\
\hline & 84 & & & & $81 \%$ & & & & & \\
\hline 72 & 31 & 117 & & & $98 \%$ & $96 \%$ & & & & \\
\hline 211 & 37 & 27 & 3 & & $97.0 \%$ & $84.7 \%$ & $75.1 \%$ & $96.8 \%$ & $83.1 \%$ & $79.6 \%$ \\
\hline \multirow[t]{3}{*}{73} & 58 & & & & $94.0 \%$ & $36.0 \%$ & & & & \\
\hline & & 133 & & & & $83 \%$ & $70 \%$ & $95 \%$ & $91 \%$ & $80 \%$ \\
\hline & 73 & & & & $97.70 \%$ & & & $100 \%$ & & \\
\hline 49 & 18 & 15 & & & $\begin{array}{r}92 \% \text { Pericardial } / 78 \% \\
\text { porcine/homograft }\end{array}$ & $35 \%$ Homograft & & & & \\
\hline
\end{tabular}

surgery, as measured by TAPSE. However, one should be careful with use of TAPSE as a parameter in this population particularly because of the high rates of previous surgeries. TAPSE is systematically reduced after cardiac surgery and does not always reflect true right ventricle dysfunction. Longitudinal right ventricle excursion is usually reduced after surgery, but if radial contraction is preserved, the ejection fraction may be normal. ${ }^{31}$ This imposes limitations to our interpretation of the echocardiography data available.

Almost no valve-related death was found in our study: there was 1 death due to hemorrhage and none due to thrombosis or reoperation. For 9 patients cause of death was unknown, so it is impossible to comment on the cause of their deaths. All-cause survival was comparable to other pulmonary valve replacement cohorts, with $95 \%$ at 5 years and $91 \%$ at 10 years. $^{25}$

\section{Limitations}

The nonrandomized and retrospective nature of this study including a number of heterogeneous populations are major limitations of this study. In addition, we updated studies that had already been published, so that publication bias undeniably plays a role. Within this population there is substantial variance; for instance, time period of inclusion, underlying cardiac conditions, and number of surgeries, contributing to heterogeneity of this cohort. Bleeding events were not registered in this study due to its historic nature and the likely underreporting inherent to such a study. In addition, local cardiologists remotely located from the center performing the operation followed-up with many patients and communications were not always recorded. Nonetheless, we have no reason to expect a higher incidence of bleeding events compared with mitral valve implantations because this is not related to the valve position but rather to INR control. Where the strength of this study lies is in its global nature. At the same time, a major limitation of the study is heterogeneity. Another limitation is the nonstandard anticoagulation management among institutions and throughout the study period, because anticoagulation control is crucial for the functional integrity of a prosthesis. ${ }^{32}$

\section{CONCLUSIONS}

A mechanical valve can be a valid choice for PVR. MPVR is associated with a limited risk of valvular thrombosis, for which thrombolysis was an effective treatment

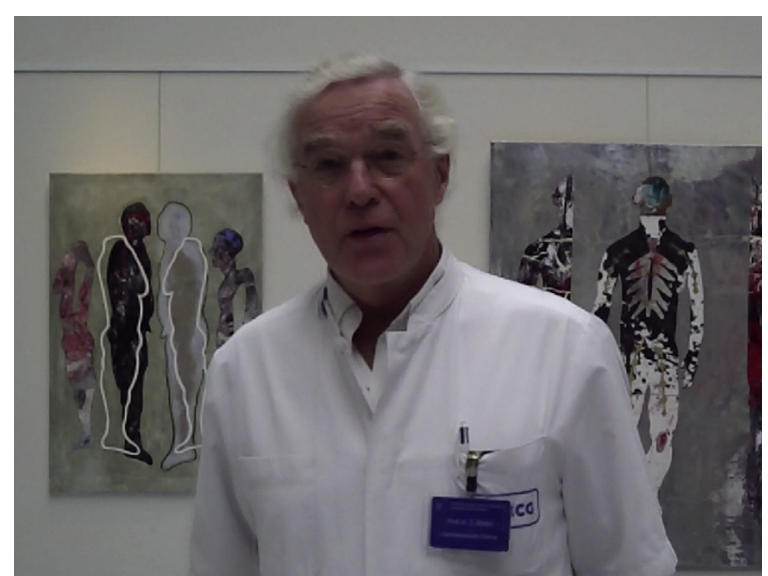

VIDEO 1. Tjark Ebels, MD, PhD, congenital thoracic surgeon at University Medical Center Groningen, explaining the importance and relevance of this work. Video available at: http://www.jtcvsonline.org/article/ S0022-5223(17)31050-4/addons. 
in the majority of affected patients. Reintervention rates over 10 years were superior to reported rates of biological aortic valvular prostheses and similar to pulmonary allografts. Nonetheless, we do not advise use of MPVR for patients with an elevated risk of thrombosis, such as women foreseeing a possible pregnancy ${ }^{33,34}$ and patients likely to be noncompliant with anticoagulation therapy (Video 1).

\section{Conflict of Interest Statement}

H.P. and T.E. own rights to a patent for a mechanical valve design for the pulmonary position. No funding was provided for this study. All other authors have nothing to disclose with regard to commercial support.

\section{References}

1. Moons P, Bovijn L, Budts W, Belmans A, Gewillig M. Temporal trends in survival to adulthood among patients born with congenital heart disease from 1970 to 1992 in Belgium. Circulation. 2010;122:2264-72.

2. Baumgartner H, Bonhoeffer P, De Groot NM, de Haan F, Deanfield JE, Galie N, et al. ESC Guidelines for the management of grown-up congenital heart disease (new version 2010). Eur Heart J. 2010;31:2915-57.

3. Lee C, Park CS, Lee CH, Kwak JG, Kim SJ, Shim WS, et al. Durability of bioprosthetic valves in the pulmonary position: long-term follow-up of 181 implants in patients with congenital heart disease. J Thorac Cardiovasc Surg. 2011;142: 351-8.

4. Henaine R, Roubertie F, Vergnat M, Ninet J. Valve replacement in children: a challenge for a whole life. Arch Cardiovasc Dis. 2012;105:517-28.

5. Dunne B, Xiao A, Litton E, Andrews D. Mechanical prostheses for right ventricular outflow tract reconstruction: a systematic review and meta-analysis. Ann Thorac Surg. 2015;99:1841-7.

6. Dehaki MG, Ghavidel AA, Omrani G, Javadikasgari H. Long-Term Outcome of mechanical pulmonary valve replacement in 121 patients with congenital heart disease. Thorac Cardiovasc Surg. 2015;63:367-72.

7. Dos L, Muñoz-Guijosa C, Mendez AB, Ginel A, Montiel J, Padro JM, et al. Long term outcome of mechanical valve prosthesis in the pulmonary position. Int $J$ Cardiol. 2011;150:173-6.

8. Freling HG, van Slooten YJ, van Melle JP, Ebels T, Hoendermis ES, Berger RM, et al. Pulmonary valve replacement: twenty-six years of experience with mechanical valvar prostheses. Ann Thorac Surg. 2015;99:905-10.

9. Hörer J, Vogt M, Stierle U, Cleuziou J, Prodan Z, Schreiber C, et al. A comparative study of mechanical and homograft prostheses in the pulmonary position. Ann Thorac Surg. 2009;88:1534-9.

10. Ovcina I, Knez I, Curcic P, Özkan S, Nagel B, Sorantin E, et al. Pulmonary valve replacement with mechanical prostheses in re-do Fallot patients. Interact Cardiovasc Thorac Surg. 2011;12:987-92.

11. Shin HJ, Kim YH, Ko JK, Park IS, Seo DM. Outcomes of mechanical valves in the pulmonic position in patients with congenital heart disease over a 20-year period. Ann Thorac Surg. 2013;95:1367-71.

12. Stulak JM, Dearani JA, Burkhart HM, Connolly HM, Warnes CA, Suri RM, et al. The increasing use of mechanical pulmonary valve replacement over a 40-year period. Ann Thorac Surg. 2010;90:2009-14.

13. Bouhout I, Stevens LM, Mazine A, Poirier N, Cartier R, Demers P, et al. Longterm outcomes after elective isolated mechanical aortic valve replacement in young adults. J Thorac Cardiovasc Surg. 2014;148:1341-6.

14. Bouchard D, Mazine A, Stevens LM, Pellerin M, Cartier R, Demers P, et al. Twenty-year experience with the CarboMedics mechanical valve prosthesis. Ann Thorac Surg. 2014;97:816-23.

15. Bryan AJ, Rogers CA, Bayliss K, Wild J, Angelini GD. Prospective randomized comparison of CarboMedics and St. Jude Medical bileaflet mechanical heart valve prostheses: ten-year follow-up. J Thorac Cardiovasc Surg. 2007;133:614-22.
16. Toole JM, Stroud MR, Kratz JM, Crumbley AJ III, Bradley SM, Crawford FA Jr, et al. Twenty-five year experience with the St. Jude medical mechanical valve prosthesis. Ann Thorac Surg. 2010;89:1402-9.

17. Nishida T, Sonoda H, Oishi Y, Tanoue Y, Nakashima A, Shiokawa Y, et al. Singleinstitution, 22-year follow-up of 786 CarboMedics mechanical valves used for both primary surgery and reoperation. J Thorac Cardiovasc Surg. 2014;147:1493-8.

18. Nishimura RA, Otto CM, Bonow RO, Carabello BA, Erwin JP III, Guyton RA, et al. 2014 AHA/ACC guideline for the management of patients with valvular heart disease: a report of the American College of Cardiology/American Heart Association Task Force on Practice Guidelines. J Thorac Cardiovasc Surg. 2014;148:e1-132.

19. Nomoto R, Sleeper LA, Borisuk MJ, Bergerson L, Pigula FA, Emani S, et al. Outcome and performance of bioprosthetic pulmonary valve replacement in patients with congenital heart disease. J Thorac Cardiovasc Surg. 2016;152: 1333-42.e3.

20. Babu-Narayan SV, Diller GP, Gheta RR, Bastin AJ, Karonis T, Li W, et al. Clinical outcomes of surgical pulmonary valve replacement after repair of tetralogy of Fallot and potential prognostic value of preoperative cardiopulmonary exercise testing. Circulation. 2014;129:18-27.

21. Oliver JM, Garcia-Hamilton D, Gonzalez AE, Ruiz-Cantador J, SanchezRecalde A, Polo ML, et al. Risk factors for prosthetic pulmonary valve failure in patients with congenital heart disease. Am J Cardiol. 2015;116:1252-6.

22. Schubert SA, Myers JL, Kunselman AR, Clark JB. Early outcomes of pulmonary valve replacement with the Mitroflow bovine pericardial bioprosthesis. Ann Thorac Surg. 2015;99:1692-9.

23. Sabate Rotes A, Eidem BW, Connolly HM, Bonnichsen CR, Rosedahl JK, Schaff HV, et al. Long-term follow-up after pulmonary valve replacement in repaired tetralogy of Fallot. Am J Cardiol. 2014;114:901-8.

24. Chen XJ, Smith PB, Jaggers J, Lodge AJ. Bioprosthetic pulmonary valve replacement: contemporary analysis of a large, single-center series of 170 cases. J Thorac Cardiovasc Surg. 2013;146:1461-6.

25. Van de Woestijne PC, Mokhles MM, de Jong PL, Witsenburg M, Takkenberg JJ, Bogers AJ. Right ventricular outflow tract reconstruction with an allograft conduit in patients after tetralogy of Fallot correction: long-term follow-up. Ann Thorac Surg. 2011;92:161-6.

26. Shinkawa T, Anagnostopoulos PV, Johnson NC, Watanabe N, Sapru A, Azakie A. Performance of bovine pericardial valves in the pulmonary position. Ann Thorac Surg. 2010;90:1295-300.

27. Fiore AC, Rodefeld M, Turrentine M, Vijay P, Reynolds T, Standeven J, et al. Pulmonary valve replacement: a comparison of three biological valves. Ann Thorac Surg. 2008;85:1712-8.

28. Van Dijck I, Budts W, Cools B, Eyskens B, Boshoff DE, Heying R, et al. Infective endocarditis of a transcatheter pulmonary valve in comparison with surgical implants. Heart. 2015;101:788-93.

29. Uebing A, Rigby ML. The problem of infective endocarditis after transcatheter pulmonary valve implantation. Heart. 2015;101:749-51.

30. Cheatham JP, Hellenbrand WE, Zahn EM, Jones TK, Berman DP, Vincent JA, et al. Clinical and hemodynamic outcomes up to 7 years after transcatheter pulmonary valve replacement in the US melody valve investigational device exemption trial. Circulation. 2015;131:1960-70.

31. Nguyen T, Cao L, Movahed A. Altered right ventricular contractile pattern after cardiac surgery: monitoring of septal function is essential. Echocardiography. 2014;31:1159-65.

32. Dürrleman N, Pellerin M, Bouchard D, Hébert Y, Cartier R, Perrault LP, et al. Prosthetic valve thrombosis: twenty-year experience at the Montreal Heart Institute. J Thorac Cardiovasc Surg. 2004;127:1388-92.

33. Pieper PG. Use of medication for cardiovascular disease during pregnancy. Nat Rev Cardiol. 2015;12:718-29.

34. Van Hagen IM, Roos-Hesselink JW, Ruys TP, Merz WM, Goland S, Gabriel H, et al. Pregnancy in women with a mechanical heart valve: data of the European Society of Cardiology registry of pregnancy and cardiac disease (ROPAC). Circulation. 2015;132:132-42.

Key Words: congenital heart disease, mechanical heart valve pulmonary valve replacement 


\section{APPENDIX E1. THROMBOLYSIS PROTOCOLS IN ORDER OF PREFERENCE}

1. Tehran:

a. Streptokinase: start with $250,000 \mathrm{IU}$, then 100,000 IU/h infusion for 24 to 72 hours. Last 2 years:

b. Reteplase: 2 successive doses of $10 \mathrm{U}$ at 30 -minute intervals,

c. Alteplase: $10 \mathrm{mg}$ stat then $90 \mathrm{mg}$ during 90-minute infusion.

d. For children Streptokinase 50 to $100 \mathrm{U} / \mathrm{kg} / \mathrm{h}$ for 48 to 72 hours.
2. Munich:

a. Alteplase: $0.5-1.0 \mathrm{mg} / \mathrm{kg}$ as short infusion for 30 60 minutes, then $0.5-1.0 \mathrm{mg} / \mathrm{kg} / \mathrm{d}$. When no result or no lab results consider local thrombolysis. Always heparin $5000 \mathrm{IU} / \mathrm{m}^{2} / \mathrm{d}$ to begin with, then tune to 1.5 to 2 times higher partial thromboplastin time (Increase of partial thromboplastin time is controversial with alteplase).

b. Urokinase systemic thrombolysis: $4400 \mathrm{U} / \mathrm{kg}$ for 10 to 20 minutes, then $4400 \mathrm{U} / \mathrm{kg} / \mathrm{h}$, urokinase local thrombolysis: $1500 \mathrm{U} / \mathrm{kg}$ for 10 to 20 minutes, then $1500 \mathrm{U} / \mathrm{kg} / \mathrm{h}$.

c. Streptokinase systemic thrombolysis: $3500-4000 \mathrm{U} /$ $\mathrm{kg}$ for 30 minutes, then $1000-1500 \mathrm{U} / \mathrm{kg} / \mathrm{h}$ for 12 to 72 hours.

TABLE E1. Cumulative incidences

\begin{tabular}{lccc}
\hline \multicolumn{1}{c}{ Event } & Time point, $\mathbf{y}$ & $\begin{array}{c}\text { Cumulative } \\
\text { incidence }\end{array}$ & $\begin{array}{c}\mathbf{9 5} \% \text { Confidence } \\
\text { interval }\end{array}$ \\
\hline Death & 5 & 0.05 & $0.03-0.08$ \\
Death & 10 & 0.09 & $0.05-0.15$ \\
Death & 15 & 0.21 & $0.12-0.33$ \\
Reoperation & 5 & 0.03 & $0.01-0.06$ \\
Reoperation & 10 & 0.09 & $0.05-0.15$ \\
Reoperation & 15 & 0.19 & $0.10-0.29$ \\
\hline Valvular thrombosis & 5 & 0.09 & $0.06-0.13$ \\
Valvular thrombosis & 10 & 0.14 & $0.09-0.19$ \\
\hline Valvular thrombosis & 15 & 0.21 & $0.13-0.30$ \\
\hline
\end{tabular}

